\title{
Improved PCR method for detecting monoclonal immunoglobulin heavy chain rearrangement in B cell neoplasms
}

\author{
I Ramasamy, M Brisco, A Morley
}

\begin{abstract}
Aims: To develop a simple, optimised, polymerase chain reaction (PCR) based method for detecting the rearranged immunoglobulin heavy chain (IgH).

Methods: Using as primers oligonucleotides (Fr2A, Fr2B) homologous to the conserved sequences to the framework II region and the joining $\left(J_{H}\right)$ region, 25 patients with $B$ cell lymphoproliferative disorders, previously characterised by Southern blotting, and three patients with light chain myeloma were studied.

Results: The PCR product from a polyclonal B cell population showed a broad band when analysed on a $3 \%$ agarose gel; DNA from B cell lines and B lymphoproliferative disorders showed a discrete band. Specificity of the amplification was confirmed by cloning and sequencing the amplified product as well as by Southern blotting with an internal probe homologous to the framework 3 region. Primers Fr2A and Fr2B detected monoclonality in three patients with light chain myeloma, while primers directed against the FrIII region showed a polyclonal response.

Conclusions: Deletions and extensive somatic mutations within the FrIII region may give false negative results with primers homologous to the region. A PCR using the method described, with a repertoire of primers homologous to the FrII and FrIII regions, will therefore increase the frequency of detection of monoclonality.
\end{abstract}

During the differentiation of B and T lymphocytes the rearrangement of the immunoglobulin and T cell receptor loci creates unique DNA sequences. ${ }^{1}$ Such rearrangements are widely exploited as markers of $B$ and $T$ cell lineage and clonality in lymphoproliferative disorders. $^{2}$

In B lymphocytes the variable region of the rearranged immunoglobulin heavy chain $\left(V_{H}\right)$ contains three hypervariable complementary determining regions (CDRI, CDRII, CDRIII) and three relatively conserved framework regions (FrI, FrII, FrIII). Several investigators have developed methods to amplify rapidly the CDRIII region of the Ig heavy chain, using as primers oligonucleotides that have homology to the conserved sequences to the FrIII regions of the $V_{H}$ gene segments and the $3^{\prime}$ end of the $\mathrm{J}_{\mathrm{H}}$ segments. $^{3-5}$ Amplification with primers binding to the $V_{H}$ and $J_{H}$ region does not proceed unless the gene is rearranged. Monoclonality in a B cell population is indicated by the production of a single discrete fragment following gel electrophoresis. The amplification product from a polyclonal population will result from a number of rearranged Ig genes, which will give rise to fragments of varying length, resulting in a broad band.

Primers complementary to the consensus regions have been developed from a limited number of $\mathrm{IgH}$ sequences and may not bind all possible $\mathrm{V}_{\mathrm{H}}$ genes. Most studies with primers homologous to the framework III region report that amplification is detected in $75-80 \%$ of cases of $\mathrm{B}$ lymphoproliferative disorder. ${ }^{46}$ Compared with the FrIII, which is sufficiently conserved to enable the use of a single primer, a panel of seven different $V_{H}$ family specific primers chosen from the FrI were required to detect Ig gene rearrangements in $94 \%$ of B lymphoid malignancies. ${ }^{7}$ The study with the FrI primers investigated 16 cases of $\mathrm{B}$ lymphoid malignancy but needs to be further investigated as a diagnostic technique, as polyclonal samples were not studied in detail. ${ }^{8}$

The failure of FrIII and FrI directed primers to detect $\operatorname{IgH}$ rearrangements in a significant percentage of $\mathrm{B}$ cell lymphoproliferative disorders may be due to somatic mutations within the FrI and FrIII regions. In a PCR reaction such mutations can cause a failure to prime with primers directed against these regions.

To overcome the problem of false negativity we have sought to develop an alternative, technically simple PCR based approach for detecting B lymphoid clonality in a routine laboratory setting, using oligonucleotides complementary to the FrII region and the $J_{H}$ segment. The primers thus flank and amplify the CDRII, FrIII, and the CDRIII region. This study describes the development of the method and its use in detecting clonal IgH gene rearrangement in patients with light chain myeloma and other B lymphoproliferative disorders.

\section{Methods}

Patients with the following diseases were studied: acute lymphocytic leukaemia (ALL) n $=9$; non-Hodgkin's lymphoma (NHL) $\mathrm{n}=7$; chronic lymphocytic leukaemia (CLL) $\mathrm{n}=4$; multiple myeloma $(\mathrm{MM}) \mathrm{n}=5$; nonneoplastic lymph node enlargement $\mathrm{n}=2$. The patients had been previously classified by histology, cell surface markers, Southern hybridisation $^{9}$ and by PCR with $\mathrm{Fr} 3 \mathrm{~A} / \mathrm{LJH}$ as primers. ${ }^{6}$ 
A further three patients with light chain myeloma were investigated:

Case $A$ A 69 year old man presented with chronic renal failure (potassium $6.1 \mathrm{mmol} / \mathrm{l}$, urea $26.4 \mathrm{mmol} / \mathrm{l}$, creatinine $0.57 \mathrm{mmol} / 1$, proteinuria for seven years). Agarose electrophoresis showed the presence of $\lambda$ light chains in the urine.

Case B A 71 year old man, with a six month history of back pain and progressive lethargy. Electrolytes showed severe renal failure (creatinine $0.9 \mathrm{mmol} / \mathrm{l}$, potassium $9.9 \mathrm{mmol} / \mathrm{l})$. Lambda light chains were detected in the urine.

Case $C$ A 70 year old man presented with anaemia, weight loss, immunoparesis and a raised ESR of $112 \mathrm{~mm} /$ hour (reference range $<23$ ). Urine electrophoresis showed a dense band identified as $\kappa$ light chains.

Monoclonal populations of non-neoplastic B lymphocytes were obtained by transforming mass populations of peripheral blood lymphocytes with Epstein Barr virus and then cloning at limiting dilutions. $T$ lymphocytes were obtained by direct cloning of peripheral blood lymphocytes at limiting dilutions. ${ }^{10}$

DNA was extracted from peripheral blood (patients with ALL, CLL), lymph node (patients with NHL) or bone marrow (patients with MM, CLL), as described before ${ }^{11}$ or by using the Applied Biosystems Nucleic Acid Extractor. Bone marrow specimens obtained at the time of diagnosis were available for cases $A$, $B$ and $C$.

POLYMERASE CHAIN REACTION TO DETECT IG REARRANGEMENTS

\section{(a) Primer design}

Consensus primers termed Fr2A and Fr2B/Pst were designed from homologous regions within the framework region, and based on 17 published DNA sequences. These were chosen to bind and amplify any of the postulated 200-300 $\mathrm{V}_{\mathrm{H}}$ segments. ${ }^{12}$ The following strategy was used. If two bases occurred with equal frequency at a certain position, a redundancy of the two bases was introduced. If more than two occurred or if one predominated then the most frequently occurring base was included. To allow directed cloning of the amplified DNA, primers ELJH/Bam and Fr2B/Pst were constructed, with the indicated restriction site.

Primers were designed to be homologous to codons 36 to 42 , and 37 to 47 respectively, of the framework 2 region.

Fr2A: $5^{\prime} \mathrm{TGGA}_{\mathrm{G}} \mathrm{TCCGC}_{\mathrm{A}} \mathrm{CAGG} /{ }_{\mathrm{C}} \mathrm{CT} /{ }_{\mathrm{C}} \mathrm{T} /$ CNGG 3' 20 base pairs

Fr2B/Pst: 5' GTCCTGCAGGCC/ ${ }_{\mathrm{T}} \mathrm{C} /{ }_{\mathrm{T}} \mathrm{CCGGA}$ ${ }_{G} A A A /{ }_{G} A /_{G}$ GTCTGGAGTGG $3^{\prime} 33$ base pairs

Fr3A was designed from homologous regions within the framework 3 region, and covered codons 86 to 92 . $^{5}$

Fr3A: 5' ACACGGCC/ ${ }_{\mathrm{T}} \mathrm{G} /{ }_{\mathrm{C}}$ TGTATTACTGT 3' 20 base pairs

To form the antisense strand, the six $J_{H}$ germline sequences showed considerable homology $^{13}$ to allow the design of primers LJH, VLJH, and ELJH. ${ }^{11}$
LfH: 5' TGAGGAGACGGTGACC $33^{\prime} 16$ base pairs

VLfH: 5' GTGACCAGGGTNCCTTGGCCCCAG 3' 24 base pairs

ELFH/Bam: 5' TGAGGAGACGGTGACCAGGATCCCTTGGCCCAG $3^{\prime} 34$ base pairs

The primers are synthesised on the Applied Biosystems Nucleic Acid Synthesiser.

\section{PCR conditions}

The reactions were carried out in a volume of $25 \mu \mathrm{l}$. The reaction mixture contained dATP, dCTP, dGTP, dTTP, primers, and template DNA in a buffer containing $10 \mathrm{mM} \beta$-mercaptoethanol, $67 \mathrm{mM}$ TRIS (pH 8.8), $16.6 \mathrm{mM}$ ammonium sulphate and $0.02 \%$ gelatin, 0.4 units of Taq polymerase (Cetus Corporation, 761 Main Ave, Norwalk, Connecticut 06859).

Reaction mixtures were covered with light mineral oil (Sigma Chemical Company, St Louis, Missouri 63178) to reduce evaporation. Amplified DNA was analysed by electrophoresis on $3 \%$ agarose in TBE buffer, $90 \mathrm{mM}$ TRIS, $90 \mathrm{mM}$ boric acid, and $2 \mathrm{mM}$ EDTA. DNA was stained with ethidium bromide and visualised under short wave length ultraviolet light. PCR was carried out in a programmable heat block, the Perkin Elmer Thermocycler (Cetus Corporation).

Three primer combinations were used: (I) 1st stage: $1.0 \mathrm{mM}$ of each dNTP, $4.5 \mathrm{mM}$ $\mathrm{Mg}^{2+}, 0.5 \mu \mathrm{g}$ of each primer $\mathrm{Fr} 2 \mathrm{~A} / \mathrm{LJH}$, with $1 \mu \mathrm{g}$ template DNA.

2nd stage: $0.24 \mathrm{mM}$ of each dNTP, $2.0 \mathrm{mMg}^{2+}, 0.05 \mu \mathrm{g}$ of each primer Fr2A VLJH, and a dilution of 1 in 5000 of 1st stage PCR product as DNA template.

Cycle conditions: Two minutes $94^{\circ} \mathrm{C}$, two minutes $50^{\circ} \mathrm{C}$, two minutes $72^{\circ} \mathrm{C}$. Routinely 40 cycles were performed, with a five minute denaturation step at $94^{\circ} \mathrm{C}$ at the beginning of the reaction and 20 minute elongation step at the end.

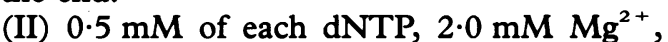
$0.05 \mu \mathrm{g}$ of each primer Fr2B/ELJH, 100 or 200 ng template DNA.

Cycle conditions: One minute $94^{\circ} \mathrm{C}$, one minute $60^{\circ} \mathrm{C}$, one minute $72^{\circ} \mathrm{C}$, for 45 cycles. A five minute denaturation at $94^{\circ} \mathrm{C}$ preceded the reaction and the last cycle included a 20 minute elongation period.

(III) PCR was performed as described by Trainor et al. ${ }^{11}$ The PCR reaction mix contained $1 \mu \mathrm{g}$ DNA template, $100 \mathrm{ng}$ of each primer Fr3A/LJH, with $0.1 \mathrm{mM}$ of each dNTP and $2.0 \mathrm{mM} \mathrm{MgCl}{ }_{2}$. For the second round PCR, the product of the first amplification reaction was diluted 1 in 1000 and amplified in a $25 \mu \mathrm{l}$ reaction volume containing, $100 \mathrm{ng}$ of each primer $\mathrm{Fr} 3 \mathrm{~A} / \mathrm{VLJH}, 0.1 \mathrm{mM}$ of each dNTP, $2.0 \mathrm{mM} \mathrm{MgCl}$.

Cycle conditions: Five minutes denaturation at $94^{\circ} \mathrm{C}$, followed by one minute at $60^{\circ} \mathrm{C}$, one minute at $72^{\circ} \mathrm{C}$ and one minute at $94^{\circ} \mathrm{C}$, for 30 cycles.

The electrophoresis of the PCR product was followed by blotting the gel on to a nitrocellu- 
lose membrane, Hybond (Amersham International, plc). The hybridisation of the Southern blot with a kinase labelled internal ${ }^{32} \mathrm{P}-\mathrm{Fr} 3 \mathrm{~A}$ probe was as described before. ${ }^{1114}$

DNA from one patient with multiple myeloma and one with non-Hodgkin's lymphoma was amplified using the primers Fr2B/Pst and $\mathrm{ELJH} / \mathrm{Bam}$, with the indicated restriction sites for directed cloning. The amplified product was cloned into the phage vectors $M 13 \mathrm{mp} 18$, M13mp19 phages and transformed into competent cells and sequenced by the dideoxy termination method, according to standard procedures. $^{14}$

\section{Results}

OPTIMISATION OF THE PCR SYSTEM

The amplified DNA was expected to be 240-260 base pairs, and to include the CDRII,
CDRIII, and FrIII regions. The variation in base numbers reflected the differences in the $\mathrm{N}$ region and variation in $\mathrm{V} / \mathrm{D} / \mathrm{J}$ joins. Reaction parameters were empirically determined to yield the least amount of non-specific products and largest amount of specific products from six B lymphocyte cell lines. Under the same conditions, little or no PCR amplified products in the expected molecular weight range were generated from six $\mathrm{T}$ lymphocyte cell lines.

By increasing the stringency of the conditions, either by raising the temperature of annealing, decreasing the concentration of the primer, or optimising the magnesium concentration in relation to the total dNTP concentrations in the reaction mixture the yield of non-specific products was decreased. In further evaluation of the parameters it was found that increasing the length of the primers was advantageous as a similar specificity was ach-
Figure 1 (A) Second stage amplification of patient DNA with Fr2A/VLfH.

Lane a: monoclonal response on a polyclonal background. Lanes $b, d, h$ : monoclonal response. Lane $c, e, f:$ polyclonal response. Lanes a-e: DNA from patients with ALL. Lane f: peripheral blood lymphocytes from healthy volunteer. Lane g: $T$ cell line. Lane $h: B$ cell line. Lane i: Control without DNA.

Amplification was in duplicate. The arrow indicates molecular weight markers of 331 and 240 base pairs.

Figure 1 (B) PCR of $D N A$ from different patients with Fr2B/ELfH as primers.

Lanes $a, b, f, h$ :

monoclonal response. Lanes $c, d, e, g, j:$ polyclonal response. Lanes a-e: DNA from patients with $A L L$. Lane f: patient with myeloma. Lane g: non-neoplastic reactive lymph nodes. Lane $h: B$ cell line. Lane $i: T$ cell line. Lane j: peripheral blood lymphocytes from healthy volunteer. Lane $k$ : control without DNA.

Arrow indicates molecular weight markers of 331 and 240 base pairs.
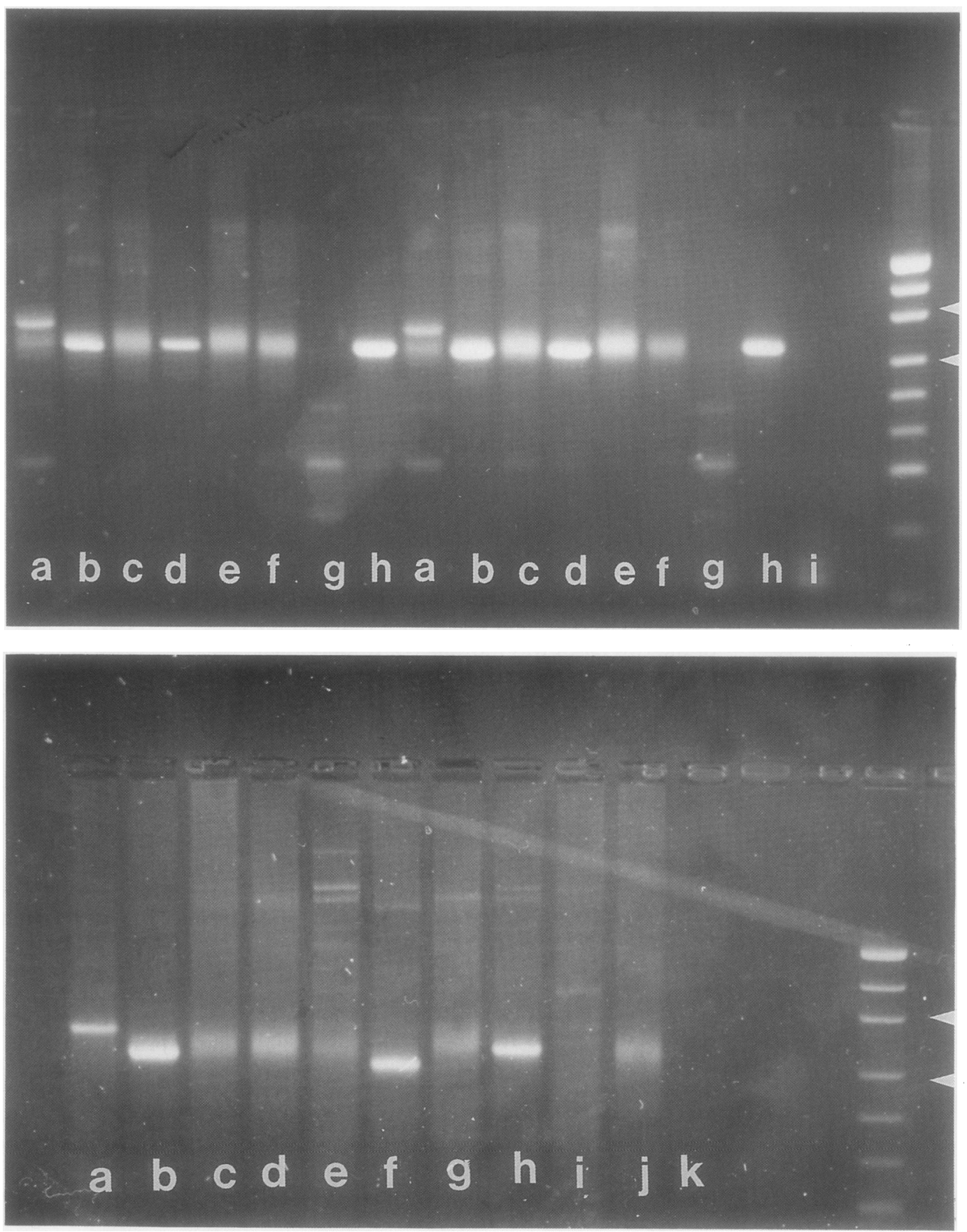
ieved by a single amplification step. The most satisfactory amplifications were found with a single step PCR with primers Fr2B/ELJH and a two step PCR with primers $\mathrm{Fr} 2 \mathrm{~A} / \mathrm{LJH}$, Stringent conditions were therefore required for specific amplification of the rearranged $\mathrm{IgH}$ gene.

A specific band with the expected molecular weight of $240-260$ base pairs was found in B cell lines as opposed to $\mathrm{T}$ cell lines, suggesting that amplification of the rearranged Ig gene found in B cell lines was achieved (figs 1A, B). Both $T$ and $B$ cell lines showed a non-specific amplification product of molecular weight 110 base pairs with the primer combination Fr2A/ $\mathrm{LJH}$, but this was not considered an interpretative problem in distinguishing cell lines with the rearranged and non-rearranged $\mathrm{Ig}$ genes. An end labelled 23 base pair internal probe Fr3A hybridised to the $240-260$ base pair PCR product (data not shown). Cloning and sequencing of the amplified product from two patients, one with multiple myeloma (MM) and one with non-Hodgkin's lymphoma (NHL), further verified that the primers Fr2B/ ELJH and Fr2A/LJH amplified the desired target sequences. A comparison of the sequence $M M$ with the sequence $V_{71-2}^{15}$ of the $\mathrm{V}_{\mathrm{H}}$ IV family showed an $85 \%$ homology, suggesting that the variable region of the heavy chain was formed from a germline sequence belonging to the $\mathrm{V}_{\mathrm{H}} \mathrm{IV}$ family and that the sequence $M M$ probably used $V_{71-2}$ as the germline sequence. If so, extensive somatic mutations had occurred in the CDRII region and base deletions had occurred around residue 89 during the formation of the $\mathrm{V}_{\mathrm{H}}$ region. The sequence NHL shows some homology to previously published sequence 9 (iii) + from the $V_{H}$ III family, ${ }^{12}$ but is most probably derived from a new germline sequence. The sequences of MM and NHL are available on request.

DETECTION OF MONOCLONAL B LYMPHOCYTE POPULATIONS

The result of a diagnostic run is shown in fig 1 (a, b). A sharp discrete band is taken as a monoclonal response, a diffuse band a polyclonal response. The gels were interpreted visually, the patient DNA samples were run in duplicate and for every 10 patient DNA samples a $B$ and $T$ cell line as well as DNA from the peripheral blood lymphocytes of a healthy volunteer and a negative control without DNA template were run as quality controls.

To assess the clinical validity of the method, 25 patients previously shown to be monoclonal by Southern blotting were studied. PCR with primers Fr2A/LJH detected monoclonal Ig

Detection of rearranged IgH gene from three light chain myeloma patients

\begin{tabular}{lllll}
\hline Case No & Fr2A/VLFH & Fr2B/ELFH & Fr3A/VLFH & Bone marrow report \\
\hline $\mathrm{A}$ & $\mathrm{M}$ & $\mathrm{M}$ & $\mathrm{P}$ & $40 \%$ of nucleated cells, plasma cells \\
$\mathrm{B}$ & $\mathrm{M}$ & $\mathrm{P}$ & $\mathrm{P}$ & $50 \%$ of nucleated cells, plasma cells \\
$\mathrm{C}$ & $\mathrm{M}$ & $\mathrm{P}$ & $\mathrm{P}$ & $59 \%$ of nucleated cells, plasma cells \\
\hline DNA was extracted from bone marrow at diagnosis and tested with the indicated primer pairs. $M=$ \\
monoclonal response; $\mathrm{p}=$ polyclonal response.
\end{tabular}

rearrangement in six of nine cases of ALL, three of four cases of $\mathrm{B}$ NHL, one of three cases of T NHL, four cases of CLL, and all five cases of MM. Monoclonality was also detected in all nine $B$ cell lines, but not in nine $T$ cell lines, in two patients with non-neoplastic reactive lymph nodes, and in polyclonal peripheral blood lymphocytes from seven healthy volunteers. The results of the double step PCR with Fr2A/LJH and a single step amplification step with Fr2B/ELJH were similar, except for a single patient with $M M$ who showed a monoclonal response with Fr2A/LJH alone.

A comparison of PCR with the FrII primers with published techniques ${ }^{96}$ showed that primers Fr2A/2B detected monoclonality in the tumours of 18 out of 19 patients previously classified as monoclonal with $\mathrm{Fr} 3 \mathrm{~A} / \mathrm{VLJH}$ and Southern blotting, but one case of B NHL failed to show monoclonality. There were three patients with ALL who showed detectable monoclonal IgH rearrangement by Southern blotting but were negative with primers directed against either FrII or FrIII regions. Three patients with T NHL who did not show IgH gene rearrangement by Southern blotting were negative with both the FrII and FrIII primers. False postive results were therefore not detected.

DETECTION OF THE REARRANGED IGH GENES IN LIGHT CHAIN MYELOMA

The advantages of the new technique were investigated in a study of three patients with light chain myeloma. The table shows that at diagnosis, the double step PCR with Fr2A/ $\mathrm{LJH}$ yielded positive results with all three patients (figs $2 \mathrm{~A}, \mathrm{~B}$ ), but one patient showed a positive result with $\mathrm{Fr} 2 \mathrm{~B} / \mathrm{ELJH}$. IgH rearrangement was not detected in all three patients with the primer pairs $\mathrm{Fr} 3 \mathrm{~A} / \mathrm{VLJH}$.

DNA from the peripheral blood samples from cases $A$ and $B$, taken at the same time, showed a polyclonal response, though a minor degree of monoclonality was detected in case B (fig 2A). In a single case (fig 2A) two heavy chain Ig gene rearrangements were observed, suggesting at least one abortive VDJ join had occurred.

\section{Discussion}

We developed a PCR technique for the analysis of B lymphoid clonality. The technique relies on the detection of Ig heavy chain VDJ rearrangement by using consensus primers against the framework II and the $\mathrm{J}$ regions of the Ig gene. The amplified product was confirmed to be the IgH gene, as it hybridised to an internal $\mathrm{V}_{\mathrm{H}}$ probe, and when sequenced contained typical VDJ rearrangements.

The FrII primers showed a monoclonal response in 18 of 22 patients shown to have clonal IgH rearrangements by Southern blotting. Similarly, 18 of 19 patients with a monoclonal response shown by FrIII primers were positive by the FrII primers. Both sets of primer combinations, Fr2A/VLH and Fr2B/ $\mathrm{ELJH}$, gave similar results. In one patient with 
Figure $2 A \quad P C R$ analysis of Ig rearrangement from case $B$, with light chain myeloma, with

Fr2A/VLFH as primers.

Lane a: bone marrow from case B. Lane b: peripheral blood lymphocytes from case B. Lane c: peripheral blood lymphocytes from healthy volunteer. Lane d: control without DNA. Lane e: $T$ cell line. Lane f: $B$ cell line. Lanes $a$ and $f$ show a monoclonal molecular weight markers of 331 and 240 base pairs. response. Arrow indicates
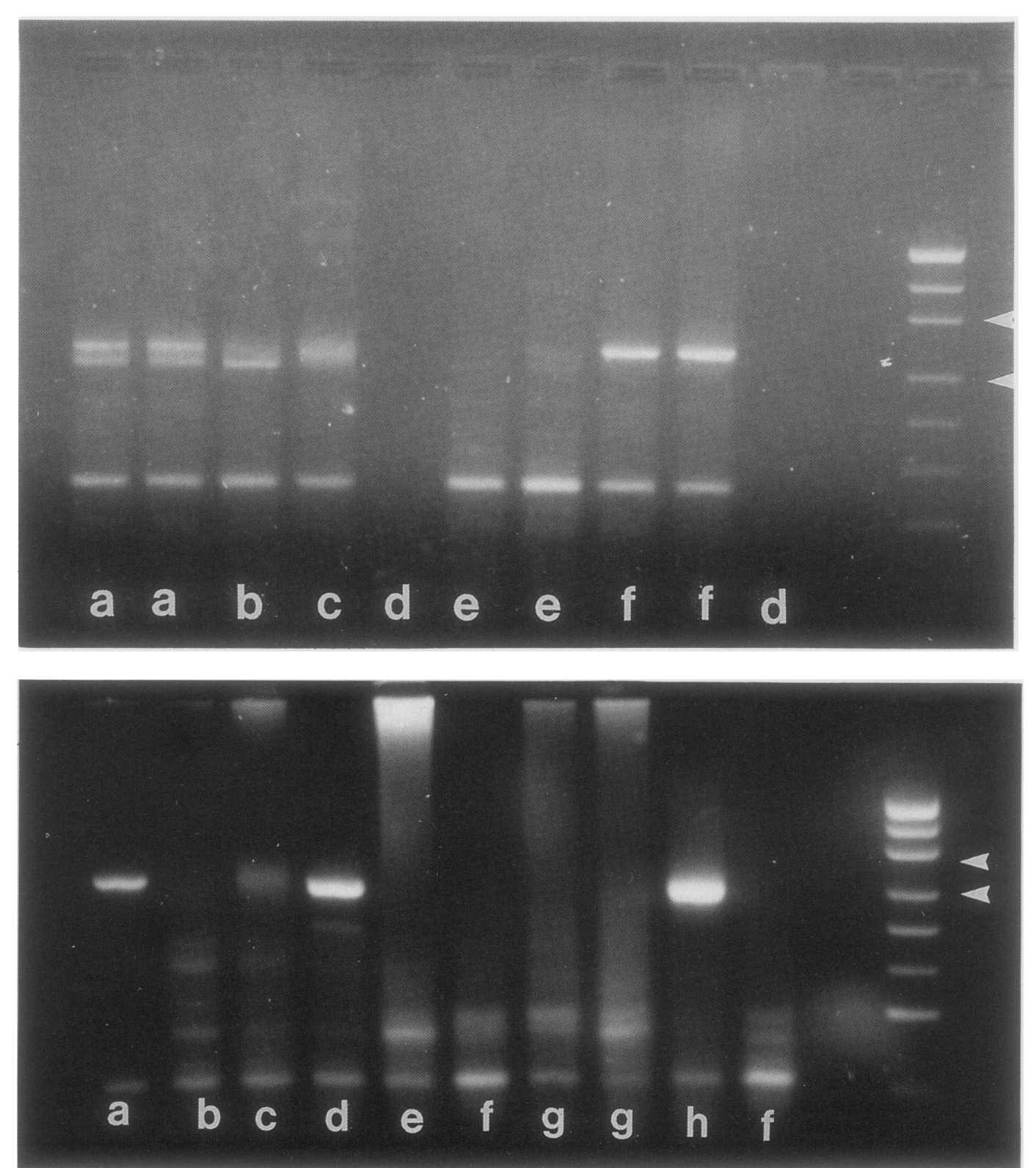

Figure $2 B \quad P C R$ analysis of Ig rearrangement from case $A$, with light chain myeloma, with

Fr2B/ELYH as primers.

Lane a: bone marrow from case $A$. Lane $b$ : peripheral blood lymphocytes from

case B. Lane c: peripheral blood lymphocytes from a healthy volunteer. Lane $d$ : bone marrow from patient with $\mathrm{mm}$. Lane e:

peripheral blood

lymphocytes from patient with $\mathrm{mm}$. Lane f: control without DNA. Lane g: T cell line. Lane $h: B$ cell

line. Lanes $a, d$, and $h$ show a monoclonal response. Lanes $d$ and $e$ are from a different $P C R$ run and are included for comparison. Arrow indicates molecular weight markers of 331 and 240 base pairs.
MM monoclonality was detected by PCR with Fr2a/VLJH, Fr3A/VLJH, and Southern blotting, but not with Fr2B/ELJH. Possible explanations for this could be suboptimal priming by the longer primers, or the greater sensitivity of the two step PCR over the technically more convenient one stage method. In this study four out of 21 patients did not show a monoclonal band despite detection of Ig heavy chain rearrangement by Southern blotting. It may be that primers complementary to the consensus region of the framework sections may not bind all of the postulated $200-300 \mathrm{~V}_{\mathrm{H}}$ segments, ${ }^{12}$ or that Southern blotting detected D-J rearrangement that did not proceed to a VDJ joining, or that the $J_{H}$ segment was involved in an unusual gene translocation.

In $B$ cell maturation the rearrangement of heavy chain genes precedes that of the light chain genes. ${ }^{16}$ Using Southern blotting and a $\mathrm{J}_{\mathrm{H}}$ probe clonal, heavy chain rearrangements have been found in the bone marrow of patients with pure Bence Jones myeloma. ${ }^{17}$
Using the polymerase chain reaction we have confirmed that rearrangements of the VDJ regions occur in tumours that secrete light chains alone. Alterations in transcription controlling elements ${ }^{18}$ or mRNA splicing signals ${ }^{19}$ can prevent the formation of a functional heavy chain protein, but at this stage it is difficult to know whether the heavy chain rearrangement is transcriptionally silent or simply defective. Heavy chain expression was, however, not detected by immunoprecipitation with antihuman heavy chain antisera in two $\kappa$ secreting myeloma cell lines SKMM1 and SKMM2. ${ }^{20}$

Heavy chain gene rearrangements in light chain myeloma patients were not detected by the Fr3A/VLJH primer combination. This may indicate a defect in the $3^{\prime}$ end of the $V_{H}$ segment. Deletion of part of the FrIII primer binding region has been observed in three out of 36 patients with ALL when the PCR amplified product was sequenced (Condon $\mathrm{J}$, Hughes E, Brisco $M$, unpublished observations). Deane et al report four cases of B NHL 
that were negative for PCR amplification of the IgH gene with an FrIII primer. ${ }^{8}$ On further investigation of two of these patients a $24 \%$ mismatch with a FrIII primer, which included a mismatch within the $3^{\prime}$ terminal bases of the primer, was identified. In such cases the primer Fr3A will anneal poorly and stable priming duplexes with the $\mathrm{V}_{\mathbf{H}}$ oligonucleotide will not be formed.

In some cases of leukaemia and lymphomas lineage and clonality may be difficult to determine using immunophenotypic methods. Studies have shown that analysis of gene rearrangements can resolve such diagnostic problems. $^{21}$ PCR is preferred to Southern blotting which is technically more complex, requires a larger amount of DNA, and is time consuming. The PCR technique can be widely applied in that it has also been successfully used for surgical biopsy ${ }^{4}$ and paraffin wax embedded sections, ${ }^{22}$ and node aspirates. ${ }^{6}$

The present technique has implications for the available strategies for the detection of minimal residual disease. Primers consensus to the FrIII and the $J_{H}$ region have been used to amplify the CDRIII region. The CDRIII region, thus amplified, is unique to each $\mathrm{IgH}$ rearrangement, and is used to generate either diagnostic oligonucleotide probes ${ }^{323}$ or PCR primers ${ }^{5}$ that do not cross hybridise with the CDRIII sequences of the normal B lymphocyte. Using such CDRIII probes residual leukaemic disease can be successfully detected in patients with $\mathrm{B}$ cell lineage malignancies. ${ }^{\mathbf{2 4}}$ Our technique increases the scope for the design of leukaemia specific oligonucleotides as it permits the sequencing of CDRII, a second hypervariable region.

The methods for detecting monoclonality that rely on consensus sequences to the framework III regions have the disadvantage that $20-30 \%$ of B cell neoplasms are not detected $^{410}$ or that efficiency of amplification of individual leukaemic alleles was highly variable. ${ }^{24}$ Similarly, the PCR technique, which relies on primers directed against the FrI region, has the disadvantage that a panel of seven different primers is required. ${ }^{7}$ Previous investigators have suggested that better primers may overcome the problem of false negative results, thus increasing the diagnostic value of the test. ${ }^{6}$

In summary, our PCR gene amplification procedure describes an approach that has the advantage of detecting IgH rearrangement which may involve unusual rearrangements in the $3^{\prime}$ region of the $V_{H}$ gene, and therefore not be amplified by primers binding to the FrIII region. In general, it is advisable to use a repertoire of primers homologous to the various framework regions to avoid the risk of false negative results. This approach increases the reliability of the detection of clonal IgH gene rearrangements as equivocal results with primers directed against a single framework region can be further evaluated by primers consensus to the other two framework regions. Such studies may also be useful in elucidating the pathogenesis of $\mathbf{B}$ cell lymphoproliferative disorders.

1 Tonegawa S. Somatic generation of antibody diversity. Nature 1987;30:575-81.

2 Arnold A, Crossman J, Bakshi A, Jaffe ES, Waldmann TA, Korsemeyer SJ. Immunoglobulin gene rearrangements as unique clonal markers in human lymphoid neoplasm. $N$ Engl f Med 1983;309:1593-9.

3 Yamada $M$, Hudson S, Tournay $\mathrm{O}$, et al. Detection of minimal disease in haematopoietic malignancies of the $\mathrm{B}$ cell lineage by using the third complementary-determining region CDRIII specific probes. Proc Natl Acad Sci ing region CDRIII sp

4 McCarthy KP, Sloane JP, Wiedemann CM. Rapid method for distinguishing clonal from polyclonal $\mathrm{B}$ cell populations in surgical biopsy specimens. $\mathcal{f}$ Clin Patho 1990?43:429-32.

5 Brisco MJ, Tan LW, Orsborn AM, Morley AA. Development of a highly sensitive assay based on the polymerase chain reaction for rare B lymphocyte clones in a polyclonal population. Br f Haematol 1990;75:163-7.

6 Trainor KJ, Brisco MJ, Wan JH, Neoh S, Grist S, Morley AA. Gene rearrangements in B and T lymphoproliferative disease detected by the polymerase chain reaction. Blood 1991;78:192-6.

7 Deane $M$, Norton JD. Immunoglobulin gene fingerprinting: an approach to the analysis of $\mathrm{B}$ lymphoid clonality in lymphoproliferative

8 Deane M, McCarthy KP, Wiedemann LM, Norton JD. An improved method for the detection of $B$ lymphoid clonality by polymerase chain reaction. Leukemia 1991;5:726-30.

9 Story CJ, Morley AA, Turner PR, Seshadri R. Diagnostic use of immunoglobulin and $T$ cell receptor gene rearrangements in lymphoproliferative disease. Aust NZ $\mathcal{Y} M e d$ 1987;17:1-9.

10 Morley AA, Trainor KJ, Seshadri R. Cloning of human lymphocytes using limiting dilution. Exp Haematol lymphocytes using

11 Trainor KJ, Brisco MJ, Story CJ, Morley AA. Monoclonality in B lymphoproliferative disorders detected at clonality in B lymphoproliferative diso

12 Berman JE, Scott JM, Bollock R, et al. Content and organisation of the human $\mathrm{Ig} \mathrm{V}_{\mathrm{H}}$ families and linkage to the Ig C $\mathrm{I}_{\mathrm{H}}$ locus. Embo $\mathcal{F}$ 1988;7:727-38.

13 Ravetch JV, Siebenlist U, Korsemeyer S, Waldemann T, Leder P. Structure of the immunoglobulin locus: characterisation of embryonic and rearranged $J$ and $D$ genes. Cell 1981;27:583-91.

14 Miniatis T, Fritisch EF, Sambrook J. Molecular cloning: a laboratory manual. Cold Spring Harbor: Cold Spring Harbor Laboratory, 1982.

15 Lee KH, Matsuda F, Kinashi T, Kodaira M, Honjo T. A novel family of variable region genes of the human novel family of variable region genes of the human
immunoglobulin heavy chain. $\mathcal{F}$ Mol Biol 1987; immunoglo

16 Alt FW, Yancopoulos GD, Blackwell TK, et al. Ordered rearrangement of immunoglobulin heavy chain variable region segments. Embo $\mathcal{F}$ 1984;3:1209-16.

17 Clofert G, Klein B, Commes T, Gihanem N, Lefranc MP, Bataille $R$. No detectable malignant $B$ cells in the peripheral blood of patients with multiple myeloma. $\mathrm{Br} \mathcal{J}$ Haematol 1989;71:357-61.

18 Grosschedl R, Baltimore D. Cell type specificity of Ig gene expression is regulated by three DNA sequence elements. Cell 1985;41:885-97.

19 Yancopoulos GD, Alt FW. Regulation of the assembly and expression of variable region genes. Ann Rev Immunol expression of vari.

20 Eton O, Scheiberg DA, Houghton AN. Establishment and characterisation of two human myeloma cell lines secreting kappa light chains. Leukemia 1989;3:729-35.

21 Lardell P, Swaby RF, Medeiros CJ, Jaffe ES, Rissl R, Stettler-Stevenson $M$. Determination of lineage and clonality in diffuse lymphomas using the polymeras chain reaction technique. Hum Pathol 1991;22:685-9.

22 Wan JH, Trainor KJ, Brisco MJ, Morley AA. Monoclonality in $B$ cell lymphoma detected in paraffin wax embedded sections using the polymerase chain reaction. $\mathcal{F}$ Clin Pathol 1990;43:888-90.

23 Jonsson OG, Kitchens RL, Scott FC, Graham Smith R Detection of minimal residual disease in acute lymphoblastic leukemia using immunoglobulin hypervariable blastic leukemia using immunoglobulin hypervariable
region specific oligonucleotide probes. Blood 1991; region specif

24 Yamada $M$, Wasserman $R$, Lange B, Relchard B, Womer RB, Rover GF. Minimal residual disease in childhood B lineage lymphoblastic leukemia. N Engl $f \mathrm{Med}$ 1990;323:448-55. 